\title{
SPATIAL VARIATIONS IN SNOW STABILITY INFERRED FROM ARTILLERY CONTROL
}

\author{
By ARTHUR Judson and Rudy M. KING \\ (Rocky Mountain Forest and Range Experiment Station, 3825 East Mulberry Street, \\ Fort Collins, Colorado 80524, U.S.A.)
}

\begin{abstract}
Decisions on snow stability are strongly influenced by the presence of fresh avalanches. An analysis of 18 pairs of controlled avalanche paths in Colorado indicates most behave independently. The study supports the hypothesis that spatial variations in slope stability are common in unstable snow.

Résumé. Variations spatiales de la stabilité de la neige d'après les declenchements d'avalanches par lanceurs. Les décisions sur la stabilité de la neige sont fortement influencées par la présence d'avalanches récentes. Une analyse de 18 paires de couloir d'avalanches contrôlés dans le Colorado indique que la plupart ont des comportements indépendants. L'étude conduit à l'hypothèse que des variations spatiales dans la stabilité des pentes sont fréquentes dans la neige instable.

ZuSAmmenfassung. Räumliche Schwankungen der Schnee-Stabilität, verursacht durch Artilleriebeschuss. Entscheidungen über die Schnee-Stabilität werden stark durch das Vorhandensein frischer Lawinen beeinflusst. Eine Analyse von 18 Paaren überwachter Lawinenbahne in Colorado zeigt, dass die meisten von ihnen sich unabhängig voneinander verhalten. Die Studie stützt die Hypothese, dass räumliche Schwankungen der SchneeStabilität häufig in lockerem Schnee auftreten.
\end{abstract}

\section{INTRODUCTION}

In the process of evaluating snow stability, avalanche forecasters sometimes conclude that slopes with a common exposure and equivalent elevation have similar levels of stability. These judgements are based on evidence of similarities in the index properties of snow and appearance of avalanches on a given exposure. But snow is a highly variable material; avalanches are rarely restricted to one aspect, and observed failure patterns suggest that local variations in stability are common. Evidence of spatial variations in snow properties is cited by Borland (1954), Keeler and Weeks (1967), Martinelli (1971), and Sommerfeld (1973, 1980). Bovis (1977) and Judson (1983) present information that suggests spatial variations in snow stability.

The mountain snow cover appears to be a randomly spaced mix of stable and unstable snow, although it is not truly random; the stability of each area over time is determined by several physical processes and prior conditions. The main purpose of stability evaluation is to determine when and where avalanches are probable. Forecasters and field personnel are highly successful in selecting the general time and approximate location of expected activity, but they still lack the ability to distinguish specific areas of high stability from those of low stability. Explosives testing, reaction of snow to the weight of a person, evidence of audible collapse noises, and sighting of fresh avalanches provide qualitative evidence of snow stability in those specific areas. The question is, how well does this information extrapolate to nearby sites? According to Judson (1983), a natural release gives only limited information about the failure potential of a nearby undisturbed slope. Judson's previous work with natural avalanches involved some unknowns. The exact time of release was questionable, and there was some uncertainty regarding the number of potential avalanche days on specific slopes. This paper analyzes spatial variations in snow stability for paths subjected to the uniform trigger of artillery control. Under these conditions, the time of occurrence and the number of avalanche days were known exactly.

\section{DATA}

Records for 105 avalanche paths subjected to artillery control by the Colorado Department of 
Highways were examined for the Front Range and San Juan Mountains. Both areas are influenced by a continental climate with frequent and light snowfalls followed by periods of good weather. The San Juan mountains have a more extensive snow cover, more large storms, smaller areas contributing blowing snow, and less visible wind effects than the Front Range (northern mountains). Mid-winter study-plot snow depths vary from 0.5 to $1.5 \mathrm{~m}$ in the Front Range and from 1.0 to $2.0 \mathrm{~m}$ in the San Juans. Dry-snow avalanches are dominant in both areas. The first avalanches reach the highways in November.

The paths examined affect highways in San Juan Mountains in south-western Colorado and the Front Range in northern Colorado. Pairs of adjacent paths were selected from groups of paths with similar terrain, aspects, elevations, and exposures. Starting zones within each of the groups were controlled from a single gun position. The standard weapon was a $75 \mathrm{~mm}$ pack howitzer using a payload of $0.7 \mathrm{~kg}$ TNT and a "super-quick" fuse setting, which gives near-surface detonation. A set firing sequence was maintained during each control episode, although the sequence was occasionally modified for operational contingencies. Multiple targets were hit in the larger starting zones.

The study was limited to controlled slab avalanches, travelling more than $50 \mathrm{~m}$ on pairs of paths whose sum of single- and joint-controlled events exceeded nine. Eighteen pairs of paths from six separate avalanche groups met this criterion during the observation period, 1951 to 1980 . Pairs were assembled from separate members of a given group in such a way that a single path could appear in more than one pair. No attempt was made to construct pairs from members of different groups, because each group contained unique sets of terrain and snow-cover conditions. With one exception, all avalanche paths considered in this study are described by Frutiger (1964); the remaining pair is from Martinelli (1974).

\section{METHOD}

$P\left(A_{i}\right)$ is defined as the probability that the $i$ th path releases after being shot (conversely, $P\left(\bar{A}_{i}\right)$ is the probability that the $i$ th path does not release). To test the hypothesis that the members of a pair of paths behave independently, a $2 \times 2$ contingency table analysis was used (Snedecor and Cochran, 1980). If the members of a pair of paths are independent, then $P\left(A_{i} A_{j}\right)=P\left(A_{i}\right) P\left(A_{j}\right)$ and $P\left(A_{i} \bar{A}_{j}\right)=P\left(A_{i}\right) P\left(\bar{A}_{j}\right)$. The significance of deviations from the independence hypothesis was assessed at $\alpha=0.05$, using tables presented by Finney and others (1963).

To display the degree of similarity between members of each pair of paths in situations of demonstrated low stability, we estimated the probability of joint avalanche events conditioned on the release of one or both paths after both were shot, denoted by $P\left(A_{i} A_{j} \mid A_{i} \Lambda A_{j}\right)$, as the ratio of the number of times both paths released to the number of times at least one of the pair of paths released after both were shot. Stable cases (both paths shot with no releases) were excluded from this analysis. The 0.40 probability used as a criterion for index potential in the earlier study of natural avalanches (Judson, 1983) was used as a general reference level for comparative purposes.

\section{Results}

\section{Contingency-table analysis}

The independence hypothesis was rejected $(\alpha=0.05)$ for 6 of the 18 pairs tested. These pairs showed patterned behavior, and are marked with an asterisk in Table I. The remaining 12 pairs exhibited nonpatterned response. The analysis was subsequently expanded to test the response of each individual path in the Seven Sisters group with the combined activity on the remaining paths. The independence hypothesis was not rejected $(\alpha=0.05)$ for any of these specially paired combinations because of the disproportionate number of stable cases for single paths compared to the larger number of unstable cases in the remaining paths as a group. The contingency-table analysis indicates that only in exceptional cases does a single path index stability on another path on a consistent basis.

\section{Joint probability analysis}

The same pairs which showed significance in the contingency table analysis exceeded the joint probability reference level $P\left(A_{i} A_{j} \mid A_{i} \Lambda A_{j}\right)=0.40$. The median was 0.30 , and there was no discernable 
TABLE I. JOINT PROBABILITIES OF ARTILLERY-INDUCED SLAB AVALANCHES ALONG MOUNTAIN HIGHWAYS IN COLORADO

\begin{tabular}{|c|c|c|c|c|c|c|c|c|}
\hline \multirow{2}{*}{$\begin{array}{l}\text { Pair } \\
\text { rank }\end{array}$} & \multirow{2}{*}{$\begin{array}{c}\text { Probability } \\
P\left(A_{i} A_{j} \mid A_{i} \wedge A_{j}\right)\end{array}$} & \multicolumn{4}{|c|}{ Number of events } & \multicolumn{2}{|r|}{ Group } & \multirow{2}{*}{$\begin{array}{c}\text { Observation } \\
\text { period }\end{array}$} \\
\hline & & $A_{i} A_{j}$ & $A_{i} \bar{A}_{j}$ & $\bar{A}_{i} A_{j}$ & $\bar{A}_{i} \bar{A}_{j}$ & Area & number & \\
\hline $1^{*}$ & 0.73 & 11 & 2 & 2 & 23 & & VI & $1964-80$ \\
\hline $2^{*}$ & 0.65 & 13 & 3 & 4 & 9 & $\dagger$ & III & $1962-74$ \\
\hline $3^{*}$ & 0.64 & 7 & 2 & 2 & 12 & & I & $\begin{array}{l}1951-58 \\
1966-68\end{array}$ \\
\hline $4^{*}$ & 0.53 & 9 & 4 & 4 & 18 & $\dagger$ & II & $1962-71$ \\
\hline $5^{*}$ & 0.50 & 5 & 5 & 0 & 8 & $\dagger$ & IV & $1961-75$ \\
\hline $6^{*}$ & 0.45 & 5 & 1 & 5 & 13 & & I & \\
\hline 7 & 0.38 & 10 & 7 & 9 & 5 & $\dagger$ & V & $1961-75$ \\
\hline 8 & 0.33 & 4 & 2 & 6 & 11 & & I & \\
\hline 9 & 0.30 & 3 & 4 & 3 & 6 & & I & \\
\hline 10 & 0.30 & 3 & 4 & 3 & 19 & & VI & \\
\hline 11 & 0.29 & 4 & 5 & 5 & 10 & & I & \\
\hline 12 & 0.27 & 3 & 2 & 6 & 12 & & I & \\
\hline 13 & 0.27 & 4 & 6 & 5 & 14 & $\dagger$ & II & \\
\hline 14 & 0.27 & 3 & 7 & 1 & 8 & $t$ & IV & \\
\hline 15 & 0.25 & 4 & 7 & 5 & 16 & $\dagger$ & II & \\
\hline 16 & 0.25 & 4 & 6 & 6 & 9 & & I & \\
\hline 17 & 0.20 & 2 & 4 & 4 & 6 & & I & \\
\hline 18 & 0.07 & 1 & 5 & 8 & 11 & & I & \\
\hline
\end{tabular}

*Significant at $\alpha=0.05$ (results of contingency table analysis).

† Pair located in southern mountains; unmarked pairs were located in the northern mountains.

difference in the likelihood of joint events in the southern or northern mountain areas. Only one pair was consistently above 0.40 every winter; this pair is ranked second in Table I. The first ranked pair had an overall joint probability of 0.73 , but like all but one of the other pairs, neither path in this pair consistently indexed the stability of the other path.

To further assess the degree of similarity in stability levels between members of each pair, we computed $P\left(A_{i} \mid \bar{A}_{j}\right)$, which is the conditional probability of releasing the second avalanche in a pair, given that control failed to release the first path. The median value for these computations was also 0.30 , a confirmation that when snow is unstable, the stability levels between individual paths close to each other are significantly different more often than they are alike.

\section{Discussion}

Both analyses indicate significant stability differences between individual paths on similar terrain. This lack of space coherence in snow stability makes the evaluation of single avalanche slopes difficult and uncertain unless they are tested with explosives. Even after explosives are used, there is a slight chance of a post-control release (Williams, 1978). Application of surface and air bursts suggested by Gubler (1977) appear to offer a partial remedy for the post-control problem. The problem of interpath stability variation is not limited to snow; analogous response characteristics are seen in the non-synchronous nature of geomorphic shifts associated with various types of mass movement in rock and soils (Schumm, 1977). Schumm cites the existence of different geomorphic thresholds in otherwise similar terrain as an explanation of the apparent random and local failure in landforms subjected to uniformly large external triggers.

Stability tests with paired paths are admittedly restrictive and do not yield information on the likelihood of failure within a larger group of paths on a given exposure. To assess this more qualitative approach to stability evaluation, probabilities of artifically releasing at least one additional avalanche from a group of similar paths were computed, given that one avalanche had just been induced by artillery. Data for what were considered to be unstable snow conditions from one group of 11 paths in Utah, and three 
groups of 8 , 9, and 13 paths in Colorado, gave probabilities ranging from 0.50 to 0.80 . These computations indicate that when general instability is suspected, the occurrence of a single slab avalanche in a group of like paths is a good indicator of further instability in that group. The amount of stability information available from avalanche events appears to be related to sample size, such that when $N=2$, an event or non-event provides inconsistent information about failure potential on an adjacent site. Understanding of the relationship between the degree of stability, the number of avalanches seen, and sample size requires further research.

\section{Conclusions}

Interpath stability differences are common in unstable snow. These stability differences are large enough that the majority of side-by-side paths behave independently. With a sample size of two and a known stability on one of the two paths, it is not possible consistently to make good stability estimates on the remaining path. Therefore, stability information from any "test slope" should not be extrapolated to any other path. When the sample size approaches 10 side-by-side paths on like terrain with a common exposure, presence of a fresh avalanche on any of the paths gives a good indication of further instability within that group, provided that overall snow conditions are rated unstable. However, even with this $N=10$ situation with one failure, it still is not possible to distinguish clearly the remaining areas of high stability from low stability in the group, even though the probability of one or more additional failures in the group is high $(P=0.50-0.80)$. Further work on this problem should help clarify these limitations and provide an objective method of estimating area stability with avalanche data.

MS. received 21 April 1983

\section{REFERENCES}

Borland, W. M. 1954. Investigation of snow conditions causing avalanches. [Third interim report.] Denver, Colorado, 5002nd U.S. Army Research and Development Unit.

Bovis, M. J. 1977. Statistical forecasting of snow avalanches, San Juan Mountains, southern Colorado, U.S.A. Journal of Glaciology, Vol. 18, No. 78, p. 87-99.

Finney, D. J., and others. 1963. Tables for testing significance in a $2 \times 2$ contingency table, by D. J. Finney, R. Latscha, B. M. Bennett, and P. Hsu. Cambridge, etc., Cambridge University Press.

Frutiger, H. 1964. Snow avalanches along Colorado mountain highways. U.S. Dept. of Agriculture. Forest Service. Research Paper RM-7.

Gubler, H. 1977. Artificial release of avalanches by explosives. Journal of Glaciology, Vol. 19, No. 81, p. 419-29.

Judson, A. 1983. On the potential use of index paths for avalanche assessment. Journal of Glaciology, Vol. 29, No. 101 , p. $178-84$.

Keeler, C. M., and Weeks, W. F. 1967. Some mechanical properties of alpine snow, Montana 1964-66. U.S. Cold Regions Research and Engineering Laboratory. Report 227.

Martinelli, M., jr. 1971. Physical properties of alpine snow as related to weather and avalanche conditions. U.S. Dept. of Agriculture. Forest Service. Research Paper RM-64.

Martinelli, M., jr. 1974. Snow avalanche sites: their identification and evaluation. U.S. Dept. of Agriculture. Forest Service. Agriculture Information Bulletin 360.

Schumm, S. A. 1977. Geomorphic thresholds and complex response of drainage systems. (In Schumm, S. A., ed. Drainage basin morphology. Stroudsburg, Pennsylvania, Dowden, Hutchinson, and Ross, p. 299-310. (Benchmark Papers in Geology, 41.))

Snedecor, G. W., and Cochran, W. G. 1980. Statistical methods. Seventh edition. Ames, Iowa, Iowa State University Press.

Sommerfeld, R. A. 1973. Statistical problems in snow mechanics. U.S. Dept. of Agriculture. Forest Service. General Technical Report RM-3, p. 29-36.

Sommerfeld, R. A. 1980. Statistical models of snow strength. Journal of Glaciology, Vol. 26, No. 94, p. $217-23$.

Williams, K. 1978. Post-control avalanche releases. (In Comptes rendus. Deuxième recontre international sur la neige et les avalanches, 12-13 et 14 avril 1978, Grenoble, France. [Grenoble], Association Nationale pour l'Étude de la Neige et des Avalanches, p. 251-63.) 